\title{
WSL9 Encodes an HNH Endonuclease Domain-Containing Protein that Is Essential for Early Chloroplast Development in Rice
}

Xingjie Zhu' ${ }^{1}$, Changling Mou', Fulin Zhang ${ }^{1}$, Yunshuai Huang ${ }^{1}$, Chunyan Yang ${ }^{1}$, Jingli Ji ${ }^{1}$, Xi Liu' ${ }^{1}$, Penghui Cao ${ }^{1}$, Thanhliem Nguyen ${ }^{1,2}$, Jie Lan', Chunlei Zhou ${ }^{1,2,3}$, Shijia Liu', Ling Jiang ${ }^{1 *}$ and Jianmin Wan ${ }^{1,3^{*}}$ (D)

\begin{abstract}
Background: The plant chloroplast is essential for photosynthesis and other cellular processes, but an understanding of the biological mechanisms of plant chloroplast development are incomplete.

Results: A new temperature-sensitive white stripe leaf 9 (ws/9) rice mutant is described. The mutant develops white stripes during early leaf development, but becomes green after the three-leaf stage under field conditions. The ws/9 mutant was albinic when grown at low temperature. Gene mapping of the WSL9 locus, together with

complementation tests indicated that WSL9 encodes a novel protein with an HNH domain. WSL9 was expressed in various tissues. Under low temperature, the ws/9 mutation caused defects in splicing of $r p / 2$, but increased the editing efficiency of rpoB. Expression levels of plastid genome-encoded genes, which are transcribed by plastid-coded RNA polymerase (PEP), chloroplast development genes and photosynthesis-related genes were altered in the ws/9 mutant.

Conclusion: WSL9 encodes an HNH endonuclease domain-containing protein that is essential for early chloroplast development. Our study provides opportunities for further research on regulatory mechanisms of chloroplast development in rice.
\end{abstract}

Keywords: Oryza sativa, Chloroplasts, RNA splicing

\section{Background}

Rice (Oryza sativa L.) is one of the most important food crops in the world and is the main food for more than one-third of the world population. Photosynthesis is a complex process that determines yield. Chloroplasts are semi-autonomous organelles that contain many genes related to photosynthesis (Mandel et al. 1996). Chloroplasts have crucial roles in plant development and growth by utilization of $\mathrm{CO}_{2}$ and biosynthesis of carbon skeletons as well as other physiological processes (Sakamoto et al. 2008; Jarvis and López-Juez 2013). Thus, it is

\footnotetext{
* Correspondence: jiangling@njau.edu.cn; wanjm@njau.edu.cn 'State Key Laboratory for Crop Genetics and Germplasm Enhancement, Jiangsu Plant Gene Engineering Research Center, Nanjing Agricultural University, Nanjing 210095, China

Full list of author information is available at the end of the article
}

essential to identify and clone genes involved in chloroplast development and function.

Nuclear-coded RNA polymerase (NEP) and plastidcoded RNA polymerases (PEP) together determine the biosynthesis and function of chloroplasts (Tiller and Bock 2014). NEP and PEP recognize different types of promoters, but some plastid genes are co-transcribed by NEP and PEP. NEP is a eukaryotic single subunit RNA polymerase encoded by nuclear genes but is located in the plastids (Liere et al. 2011). PEP is a large, complex protein composed of core subunits and additional proteins (Hajdukiewicz et al. 1997). Chloroplast RNAs need to be processed to become functional rRNAs and mRNAs. Many RNA-binding proteins are involved in RNA cleavage, editing, splicing and stability (Tillich and Krause 2010). RNA splicing is a processing event in which the introns of a precursor messenger RNA (pre-

\section{Springer Open}

(๑) The Author(s). 2020 Open Access This article is licensed under a Creative Commons Attribution 4.0 International License, which permits use, sharing, adaptation, distribution and reproduction in any medium or format, as long as you give appropriate credit to the original author(s) and the source, provide a link to the Creative Commons licence, and indicate if changes were made. The images or other third party material in this article are included in the article's Creative Commons licence, unless indicated otherwise in a credit line to the material. If material is not included in the article's Creative Commons licence and your intended use is not permitted by statutory regulation or exceeds the permitted use, you will need to obtain permission directly from the copyright holder. To view a copy of this licence, visit http://creativecommons.org/licenses/by/4.0/. 
mRNA) are removed and its exons are joined. At present, many splicing factors have been isolated and identified, most of which are PPR (pentatriceptide repeat proteins) proteins, chloroplast RNA splicing and ribosome maturation (CRM) domain proteins and some other splicing factors (de Longevialle et al. 2010). In plants the main type of RNA editing is C-to- $\mathrm{U}$, first described in plant mitochondria by Covello and Gray (1989). A similar phenomenon was later observed in plant chloroplasts (Hoch 1991). Many RNA editing factors have been identified, including pentatricopeptide repeat (PPR) proteins, multiple organelle RNA editing factors (MORF), organelle RNA recognition motif (ORRM) containing proteins, protoporphyrinogen IX oxidase1 (PPO1) and organelle zinc finger1 (OZ1). Several PPR genes in rice, such as OsV4, WSL, WSL4, OsPPR6, OsPGL1, and WSL5, function in chloroplast biogenesis, RNA editing, RNA splicing, and chloroplast development (Gong et al. 2014; Tan et al. 2014; Wang et al. 2017; Tang et al. 2017; Xiao et al. 2018; Liu et al. 2018).

$\mathrm{HNH}$ motif is about 35 amino acids long and refers to the three most conserved His and Asn amino acid residues in the motif (Galburt and Stoddard 2002; Mehta et al. 2004; Stoddard 2006). HNH proteins include a range of nucleases such as some homing endonucleases, colicins, and restriction endonucleases (Pommer et al. 1999; Ku et al. 2002; Hsia et al. 2004; Saravanan et al. 2004; Shen et al. 2004; Cymerman et al. 2006). HNH motif allows DNA-binding and nuclease activities and plays important roles in many cellular processes, CRN13s contain an endonuclease $\mathrm{HNH}$-like motif and are involved in plant immune responses (Ramirez-Garcés et al. 2015). The chloroplast $p s b A$ gene of the unicellular green alga Chlamydomonas reinhardtii was shown to contain four large group-I introns based on partial sequence analysis (Erickson et al. 1984). Cr.psbA-4 contains an HNH motif and belongs to the HNH family (Holloway et al. 1999). However, the functions and regulatory mechanisms of proteins containing $\mathrm{HNH}$ motifs in rice remain to be elucidated.

In this study, we isolated and characterized rice mutant white stripe leaf 9 (wsl9), which showed white-striped leaves at the early seedling stage. The wsl9 mutant was albinic when grown at low temperature. We isolated the WSL9 gene by map-based cloning and demonstrated that it encodes an uncharacterized protein containing an $\mathrm{HNH}$ domain. Further investigation showed that RNA editing sites in $r p o B$ were affected by the mutation and plastidencoded gene $r p l 2$ was not completely spliced in the ws $l 9$ mutant under low temperature.

\section{Results}

\section{Phenotypic Characteristics of the ws/9 Mutant}

The mechanisms of chloroplast development were studied in a white-striped leaf mutant wsl9, identified following ethyl methane sulfonate (EMS) mutagenesis of japonica cultivar Ninggeng 3 . The leaves of the wsl9 mutant exhibited white-striped leaves up to the third-leaf stage when planted in the field (Fig. 1a). Chlorophyll (Chla, Chlb) and carotenoid contents were reduced in wsl9 mutant seedlings (Fig. 1b). Mutant plants become green from the fourth leaf stage and can not be distinguished from the wild type (WT) (Fig. 1c).

We compared the ultrastructures of chloroplasts between white sectors of wsl9 mutant leaves and WT leaves at the three-leaf stage by transmission electron microscopy (TEM). WT plants had dense and normal grana stacks (Fig. 2a, b) whereas those of the wsl9 mutant had no organized lamellar structures (Fig. 2c, d).

The wsl9 mutant was sensitive to temperature. We planted WT and the wsl 9 mutant at $20^{\circ} \mathrm{C}, 25^{\circ} \mathrm{C}$, and $30^{\circ} \mathrm{C}$. When planted at $20^{\circ} \mathrm{C}$, ws $l 9$ plants were albinic (Fig. 3a), and chlorophyll (Chl) contents were very low (Fig. 3b). At $25^{\circ} \mathrm{C}$ wsl9 plants exhibited white striping and reduced chlorophyll contents (Fig. 3c, d) and at $30^{\circ} \mathrm{C}$ the mutant could not be distinguished from the WT (Fig. 3e, f).

\section{Map-Based Cloning of the WSL9 Locus}

Genetic analyses indicated that the mutant phenotype was due to a single recessive allele. We isolated the WSL9 allele by map-based cloning. The WSL9 locus was initially located to a $89 \mathrm{~kb}$ region between InDels N12 and N3-11 on chromosome 3 in an $\mathrm{F}_{2}$ population from cross ws $19 \times$ 93-11. Sixteen open reading frames (ORFs) were predicted in the region (Fig. 4a). We sequenced the entire region in normal and mutant plants and found a SNP (G to T) in ORF Os03g0169800 at position $383 \mathrm{bp}$ from the ATG start codon. This SNP caused a cysteine to phenylalanine amino acid substitution in the mutant. We used dCAPs markers to confirm the mutant site (Fig. 4c).

To confirm that the mutation was responsible for the wsl 9 mutant phenotype we performed a complementation analysis by transforming the wsl9 mutant with the WSL9

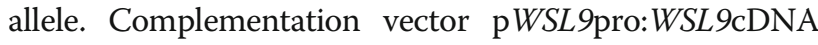
containing a $2.1 \mathrm{~kb}$ upstream sequence and the entire coding region of WSL9 was constructed and introduced into wsl9 homozygotes. Nine positive transgenic plants displayed the wild-type phenotype (Fig. 4d). These results confirmed that OsO3g0169800 was the WSL9 gene.

Analysis of the WSL9 protein in the NCBI database (https://www.ncbi.nlm.nih.gov/) showed that it encodes an uncharacterized protein containing an $\mathrm{HNH}$ domain (Additional file 4: Fig. S1a). WSL9 encodes a protein that contains a $\mathrm{HNH}$ motif in its $\mathrm{C}$ terminal, so it is possible that WSL9 may have endonuclease activity. Previous reports consider that most characterized $\mathrm{HNH}$ proteins possess endonuclease activity. However we failed to detect the endonuclease activity using WSL9 expressed in 


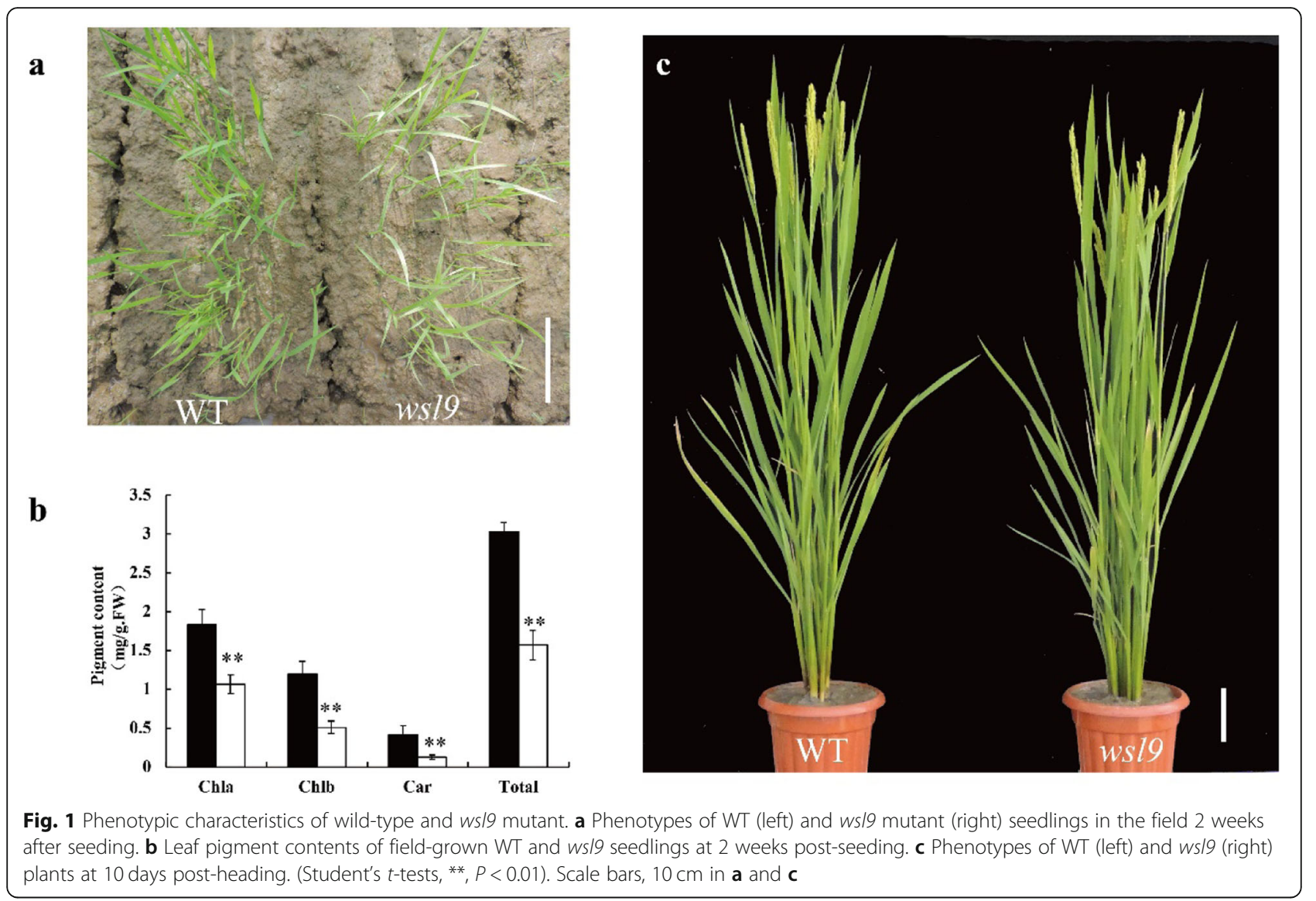

E. coli. Future work will aim to identify if WSL9 require other cofactor to act with its endonuclease activity. BLAST searches found that WSL9 had close homologs in Arabidopsis thaliana, Zea mays, Sorghum bicolor, Brachypodium distachyon, and Gossypium hirsutum (Additional file 4: Fig. S1b). The functions of all homologs were unclear. As shown in Additional file 4: Fig. S1c the mutation site was conserved in all species.

\section{Expression Pattern of WSL9 Gene}

We analyzed the WSL9 expression in different sections of leaves at various leaf development stages and the results showed that WSL9 was most highly expressed in leaf section L5 (Fig. 5a). Using the Rice XPro transcript profling database (http://ricexpro.dna.affrc.go.jp) we found that WSL9 was expressed in all tissues (Additional file 5: Fig. S2). To certify the data we performed quantitative reverse transcription-PCR (qRT-PCR) using RNA samples from different tissues of WT plants. WSL9 was expressed in various organs including the young leaves, roots, stems, sheaths, panicles and old leaves. However, WSL9 transcript was preferentially expressed in young leaves (Fig. 5c).
The ws/9 Mutant Is Defective in Plastid Transcription and Synthesis of Chloroplast Proteins

Based on promoter structure, plastid-encoded genes can be defined into three classes (class I, II and III). As previously reported Class I genes are predominantly transcribed by PEP including $p s a A, p s b A$ and $r b c L$. atpB was selected as a class II gene which is transcribed by both NEP and PEP, and rpoA, rpoB, rpoC1 and rpoC2 were selected as class III genes which are exclusively transcribed by NEP (Swiatecka-Hagenbruch et al. 2007). Expression patterns of transcripts of all genes in the wsl9 mutant and WT were very similar when the plants were grown at $30^{\circ} \mathrm{C}$ (Fig. 6a). However, at $20^{\circ} \mathrm{C}$ expression levels of class I genes were greatly reduced. In particular, expression of $r b c L$, which encodes the large subunit of Rubisco, was reduced in wsl9 mutant at $20^{\circ} \mathrm{C}$ (Fig. 6b). Rubisco activase (RCA) is a nuclear-encoded, soluble chloroplast enzyme (Andrews 1996; Spreitzer and Salvucci 2002) that regulates the activity of rubisco was also reduced in wsl 9 mutant at $20^{\circ} \mathrm{C}$ (Fig. $6 \mathrm{~b}$ ). These results suggested that wsl9 mutant was defective in PEP activity.

The chloroplast ribosome consists of $50 \mathrm{~S}$ and $30 \mathrm{~S}$ subunits. Both subunits are comprised of rRNAs (23S, 16S, 

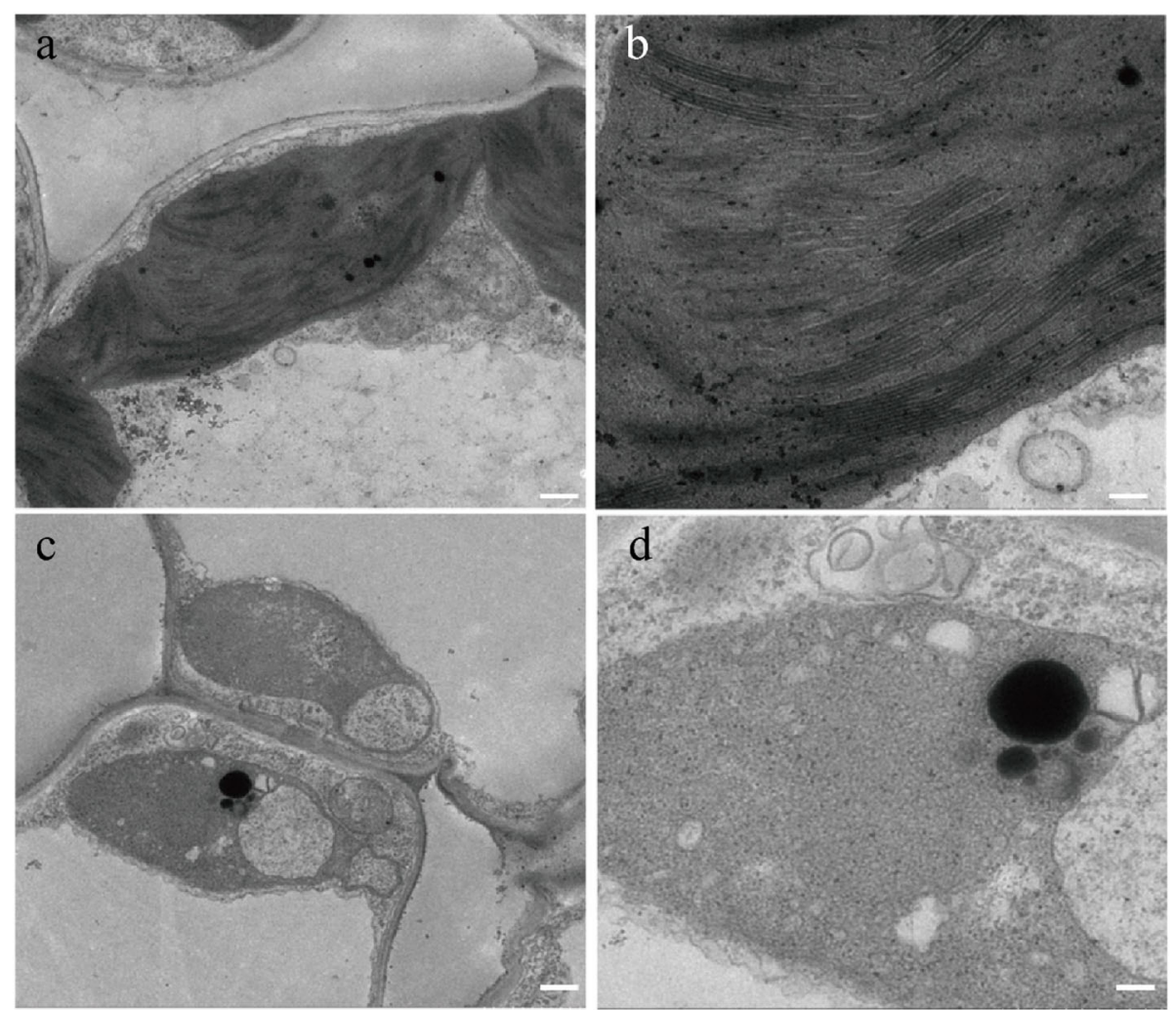

Fig. 2 Transmission electron microscope images of chloroplasts in WT (a, b) and wsl9 mutant (c, d) seedlings. Scale bar, 0.25 um in a, c; 0.15 um in $(\mathbf{b}, \mathbf{d})$

5S, and 4.5S) and ribosomal proteins. We analyzed the composition and contents of rRNAs using an Agilent 2100 instrument in plants grown at $20^{\circ} \mathrm{C}$ and $30^{\circ} \mathrm{C}$. $23 \mathrm{~S}$ and $16 \mathrm{~S}$ rRNAs were significantly decreased in wsl9 seedlings grown at $20^{\circ} \mathrm{C}$, but no difference from WT was detected at $30^{\circ} \mathrm{C}$ (Fig. 6c-f). Thus the wsl9 mutant was defective in plastidic ribosome biogenesis under low temperature conditions.

\section{The ws/9 Mutation Affects RNA editing and Splicing of rp/2 Introns}

We attempted to determine the function of WSL9. Based on a coexpression database (http://ricefrend.dna.affrc.go. jp/) and CREP (http://crep.ncpgr.cn) Module Gene Correlator analysis. We found WSP1 is one of co-expression genes of WSL9. WSP1 showed a high sequence similarity with MORF proteins (Zhang et al. 2017). Although MORFs have only been implicated in RNA editing (Ichinose and Sugita 2016), several examples of intron splicing dependent on RNA editing events have been reported (Hubschmann et al. 1996; Castandet et al. 2010; Farre et al. 2012). In addition, proteins encoded by plastid development-related genes, including ribosomal protein and PPR proteins, were among the co-expressed genes. PPR are also involved in RNA splicing and editing (de Longevialle et al. 2010). On the basis of the results above we investigated whether WSL9 affected editing at 21 previously identified RNA editing sites in chloroplast RNA (Corneille et al. 2000). The editing efficiency of rpoB at $\mathrm{C} 467$ and $\mathrm{C} 560$ showed a significant increase in wsl9 mutant compared with WT at $20^{\circ} \mathrm{C}$ (Additional file 6 Figure S3), whereas the other 10 genes and corresponding 19 editing sites were unaffected. As expected, the editing efficiency of $r p o B$ at C467 and C560 showed marked reductions in complemented plants at $20^{\circ} \mathrm{C}$ (Additional file 6 Figure S3). The rice chloroplast genome contains 17 group II introns and one group I intron (Hiratsuka et al. 1989). We carried out RT-PCR using primers flanking the introns, and then compared the lengths of the amplified products between WT and wsl9 mutant. The chloroplast $r p l 2$ transcript was spliced with greatly reduced efficiency in wsl9 mutant compared to WT at $20^{\circ} \mathrm{C}$ but not at $30^{\circ} \mathrm{C}$ (Fig. 7). The splicing defect was rescued in complemented plant (Fig. 8b). Western blotting showed that RPL2 was present at lower levels in the wsl9 mutant compared with WT and complemented plant under $20^{\circ} \mathrm{C}$ (Fig. 8c). These results 

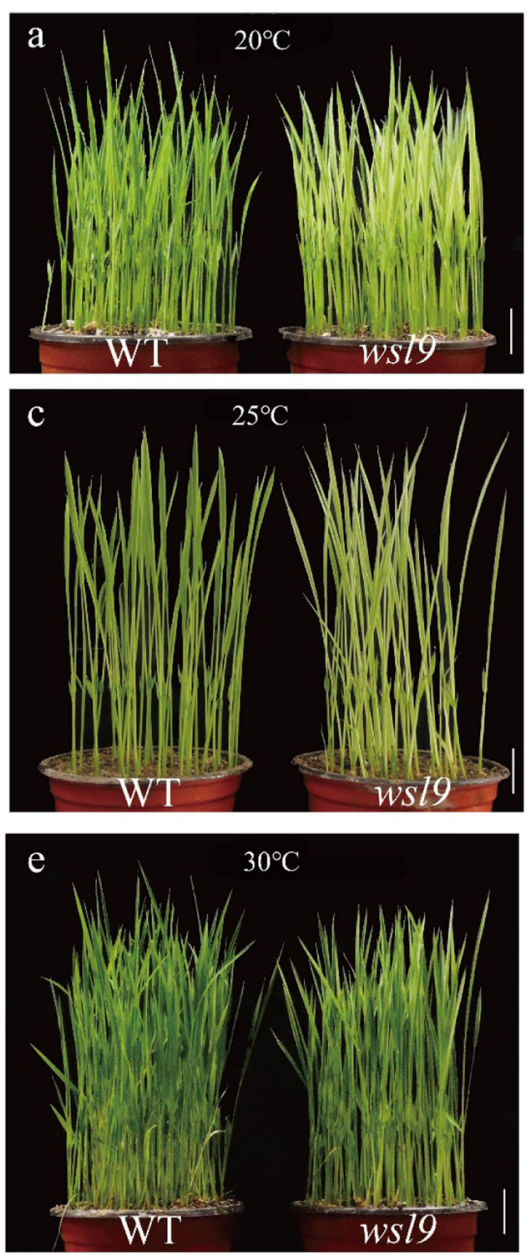

b

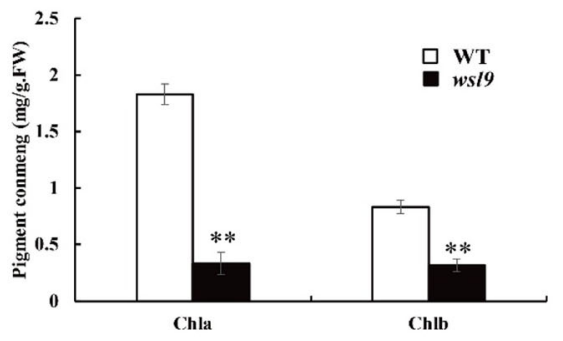

d

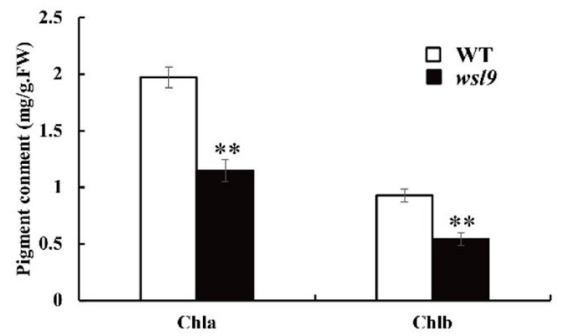

f

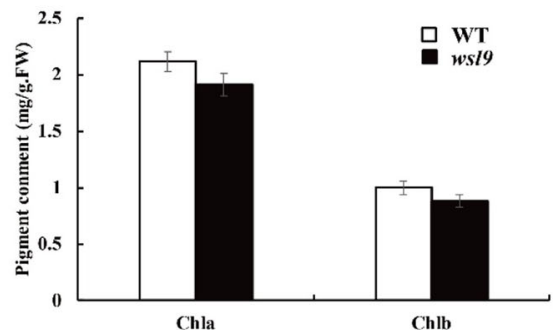

Fig. 3 Responses of the ws $/ 9$ mutant to temperature. a, c, e WT and ws $/ 9$ mutant seedlings grown at $20^{\circ} \mathrm{C}, 25^{\circ} \mathrm{C}$, and $30^{\circ} \mathrm{C}$. Scale bar, $2 \mathrm{~cm}$. $\mathbf{b}, \mathbf{d}$, f. Chl a and Chl b contents in L3-3 leaves from WT and ws/9 mutant seedlings $(\boldsymbol{n}=3)$ grown in a growth chamber with the same conditions as $(\mathbf{a}, \mathbf{c}, \mathbf{e})$ (Student's $t$-tests, $* *, P<0.01)$

suggested that the wsl9 mutant caused defects in the splicing of $r p l 2$ especially under low temperature.

\section{Differentially Expressed Genes in ws/9 Mutant and Wild Type at Different Temperatures}

We used RNA-seq to explore the effect of wsl9 on gene expression at different temperatures. A total of 48 million clean reads were obtained from wild type and ws 19 mutant plants grown at $20^{\circ} \mathrm{C}$ condition (Fig. 9a, b). We randomly selected 4 down-regulated and 5 up-regulated genes from $20^{\circ} \mathrm{C}$ data to confirm the results of RNAseq. The data for $30^{\circ} \mathrm{C}$ are shown in Additional file 8: Figure. S5. There were 1394 up-regulated and 1107 down-regulated genes in ws $l 9$ at $20^{\circ} \mathrm{C}$, compared with 888 up-regulated and 247 down-regulated genes at $30^{\circ} \mathrm{C}$ (Additional file 9: Figure. S6). Go enrichment analysis indicated that genes involved in biological adhesion, rhythmic process, extracellular matrix, structural molecular photosynthesis, PSII, and chloroplast thylakoid were significantly reduced in the $w s l 9$ mutant at $20^{\circ} \mathrm{C}$ (Additional file 9: Figure. S6). These results indicated that the WSL9 mutation led to change in many physiological processes under low temperature. For example, various chlorophyll synthesis genes, including HEMA, HEML, HEMB, URO-D,CHLH, CHLI, CHLM, CRD, DVR, POR, and $C H L G$ were significantly reduced at $20{ }^{\circ} \mathrm{C}$ (Additional file 7: Figure. S4).

\section{Discussion}

Numerous rice leaf color mutants have been reported in rice and numerous other species. Seedling leaf color mutants can be divided into albinic, striped, pale-green, and zebra according to phenotypic pattern. In this study, we identified and characterized a white-striped rice seedling mutant caused by a recessive allele designated as wsl9. Under field conditions the striped phenotype was expressed only until the third leaf stage after which the plants developed a normal green phenotype that was 


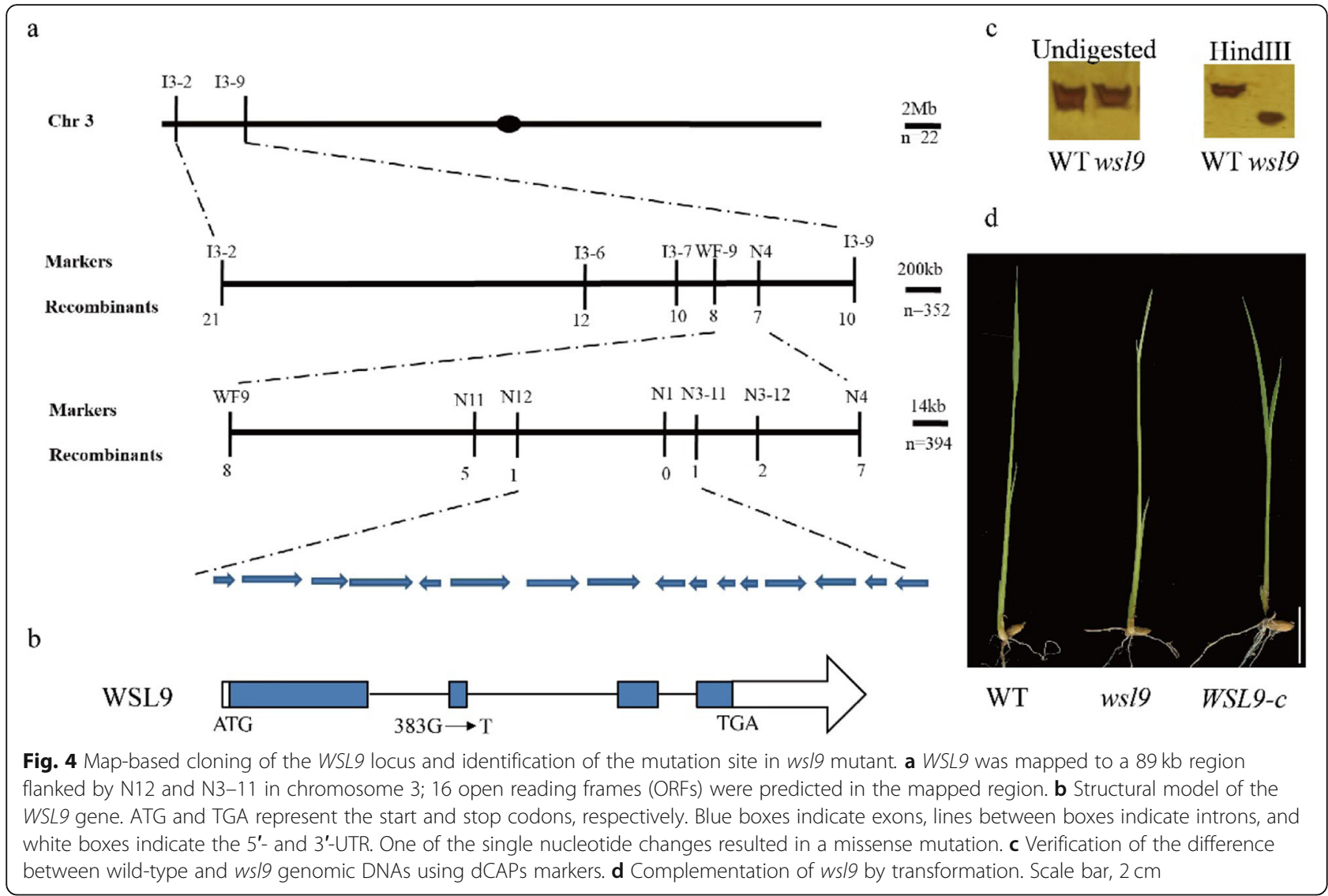

a
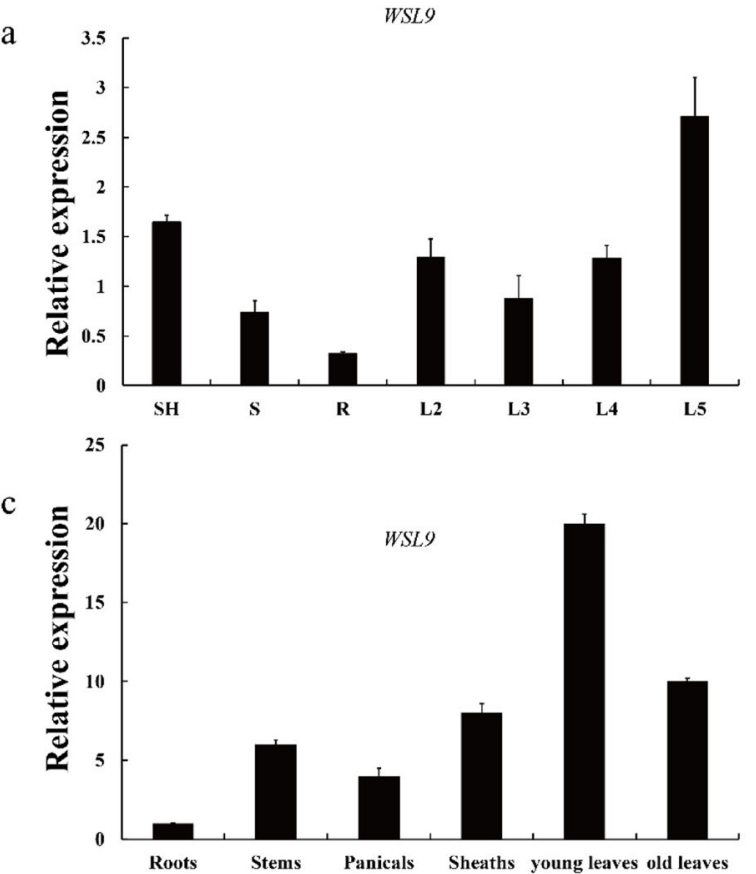

b

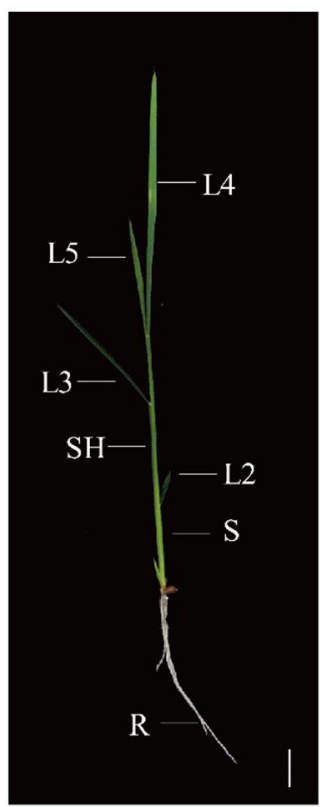

Fig. 5 Expression pattern analysis of WSL9. a qRT-PCR analysis of WSL9 transcripts in the $S H, S, R$, L2, L3, L4, L5 of wild-type seedlings. Wild-type plants at the five-leaf stage were used for expression analysis. L2-L5 indicate the second to fifth leaves. R, root; S, stem; SH, a $4 \mathrm{~cm}$ piece from the bottom of the shoot. $\mathbf{b}$ Rice seedling with fully expanded fifth leaf. Scale bar, $2 \mathrm{~cm}$. c qRT-PCR analysis of WSL9 transcripts after heading 


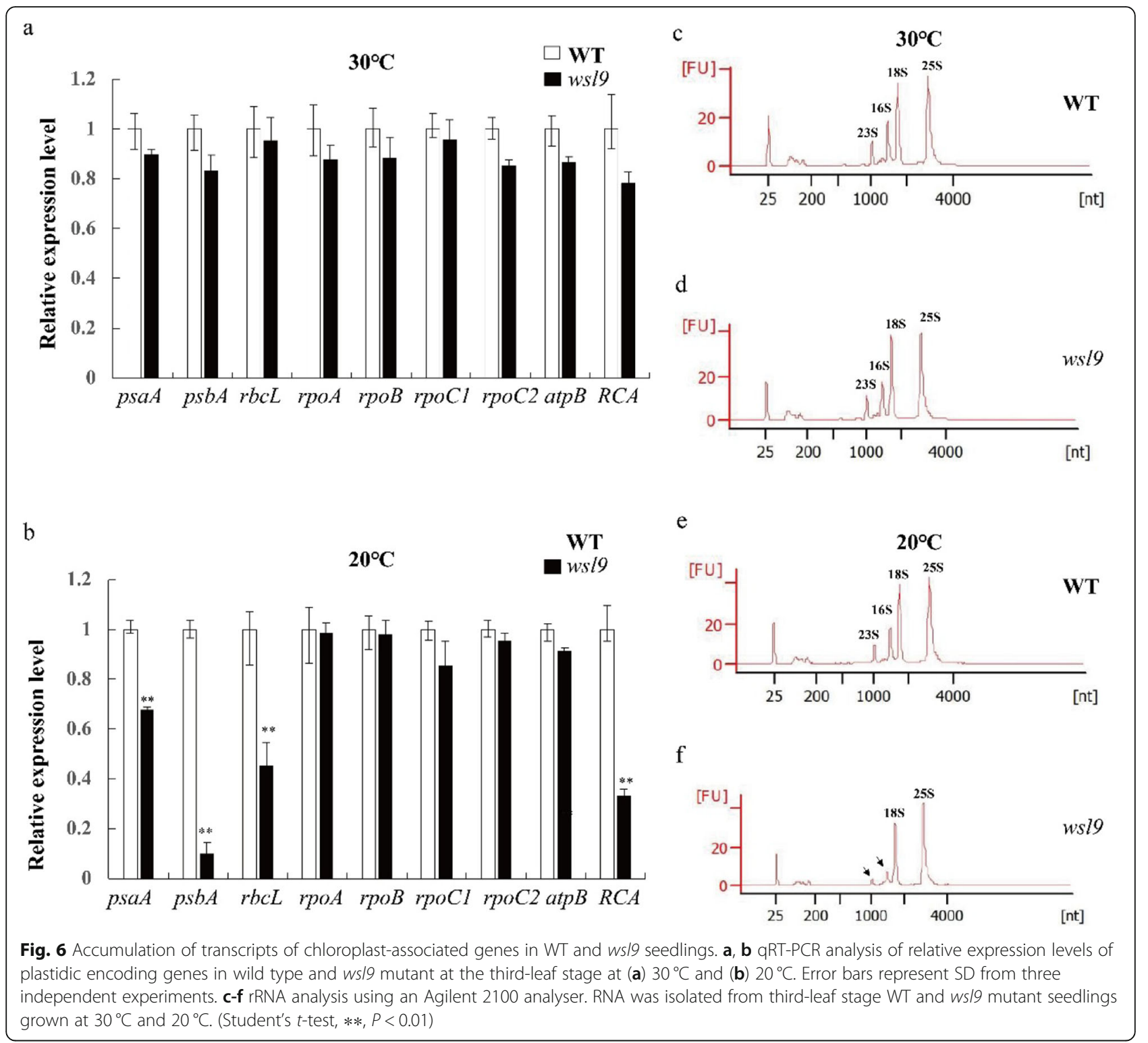

identical to the WT. The mutant phenotype was temperature-sensitive under controlled conditions (Fig. 3); it was albinic when plants were grown at $20^{\circ} \mathrm{C}$, exhibited white stripes at $25^{\circ} \mathrm{C}$, and was identical to WT at $30^{\circ} \mathrm{C}$ (Fig. 3). The transcription levels of genes associated with Chl biosynthesis and photosynthesis in ws 19 mutant were affected at the lower temperature. Many previously reported leaf color mutants were also low temperature sensitive, including $v 1, v 2, v 3$, str, ysa, wlp1, and val1 (Kusumi et al. 2011; Sugimoto et al. 2007; Yoo et al. 2009; Su et al. 2012; Song et al. 2014; Zhang et al. 2018). V1 encodes a chloroplast-located NUS1 protein that is essential for establishing the plastid genetic system during early development (Kusumi et al. 2011). V2 encodes a guanylate kinase that is located in both plastids and mitochondria and functions in chloroplast differentiation (Sugimoto et al.
2007). V3 and STR1 encoding the large and small subunits of ribonucleotide reductase, respectively, are mainly involved in DNA synthesis and repair during early leaf development (Yoo et al. 2009). YSA encodes a PPR protein with 16 tandem PPR motifs; the ysa mutant is albinic before the three-leaf stage but gradually becomes green from the four-leaf stage (Su et al. 2012). WLP1 encodes a ribosome L13 protein; early seedling leaves and immature panicles of $w l p 1$ mutant are albinic, and the phenotype is more strongly expressed at low temperatures (Song et al. 2014). VAL1 is a crucial enzyme in de novo purine biosynthesis and is involved in regulating chloroplast development and chlorophyll metabolism during leaf development (Zhang et al. 2018). Most of these mutants become green from the four-leaf stage. The wsl9 mutant likewise gradually turned green from the four-leaf stage 


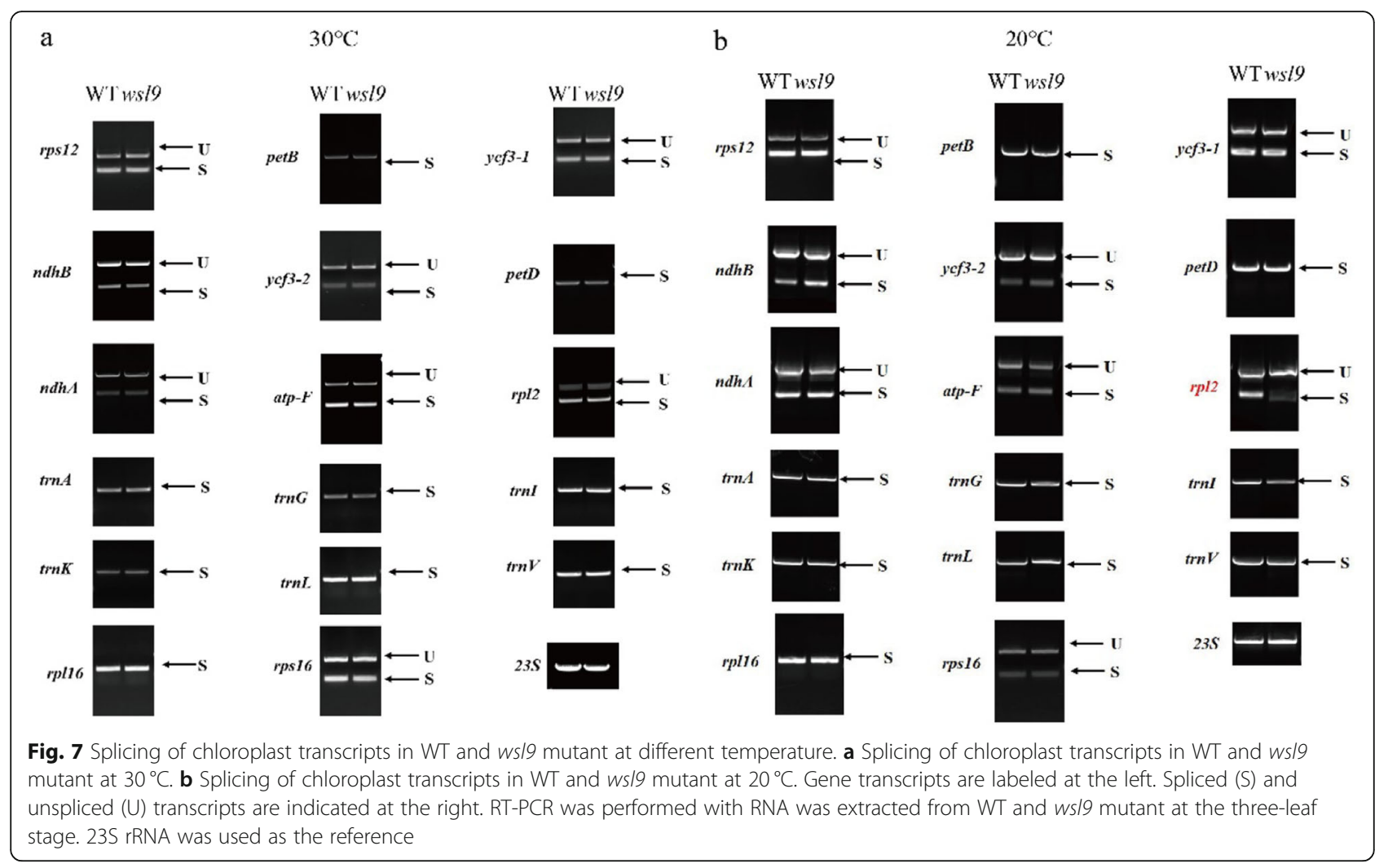

under field conditions. Transcription by NEP and PEP is a general mechanism of group-specific gene regulation during chloroplast development through recognition of distinct promoters (Hedtke et al. 1997). Previous studies showed that defects in PEP affect the development of chloroplasts and cause changes in leaf pigmentation. PEPdependent genes ( $p s a A, p s b A, r b c L)$ were reduced in wsl9 mutant at $20^{\circ} \mathrm{C}$ which suggested that the wsl9 mutant was defective in PEP activity under low temperature. This is consistent with phenotypes of the PEP-deficient mutants such as wp1, wsl5,gars (Wang et al. 2016; Liu et al. 2018; Cao et al. 2019). WSL9 is not the member of PEP complex and might not directly regulate the expression of photosynthesis-related genes. Down regulation of photosynthesis-related genes is caused by chloroplast development abnormality.

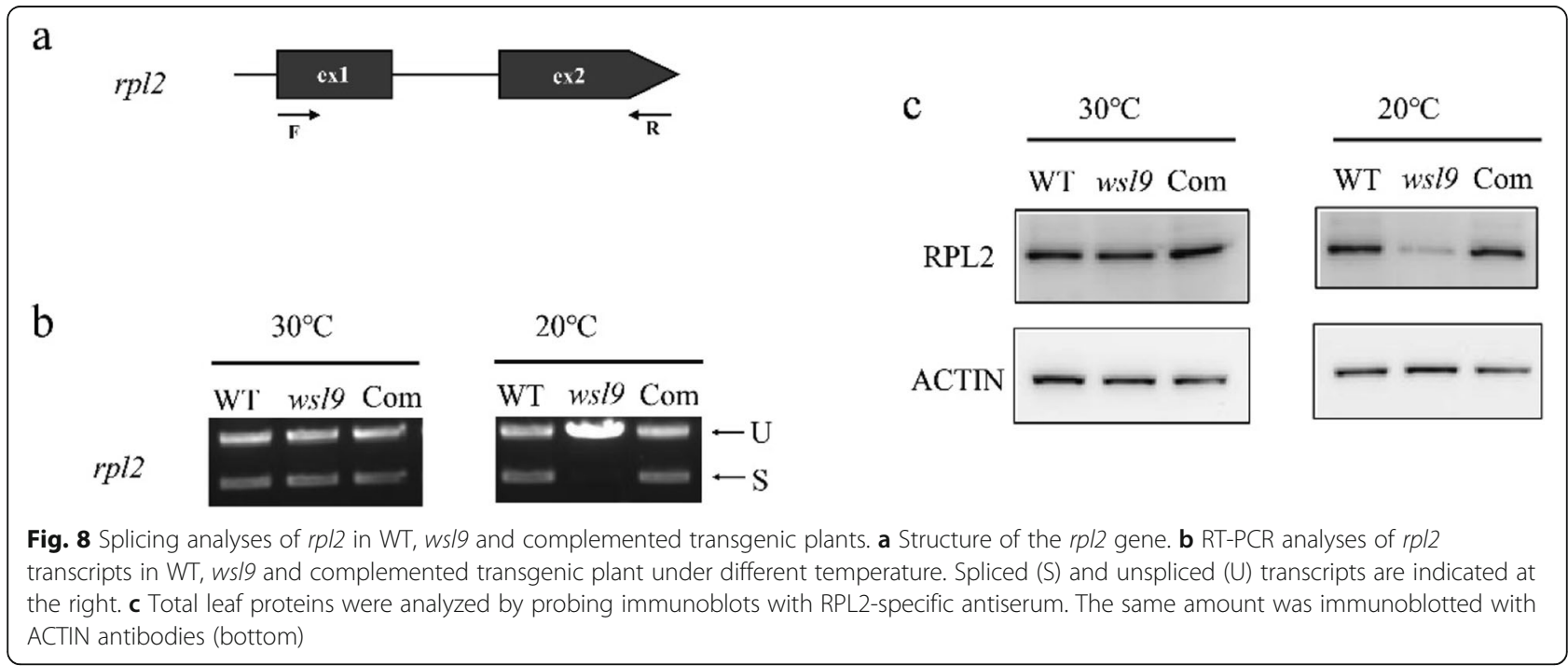



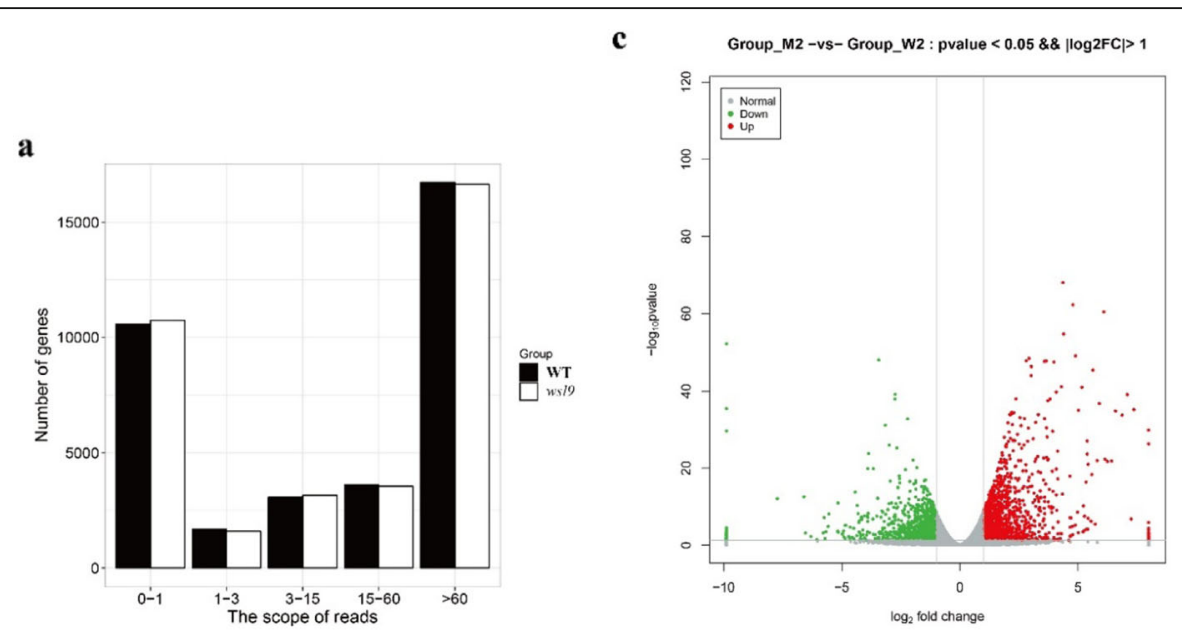

d

b

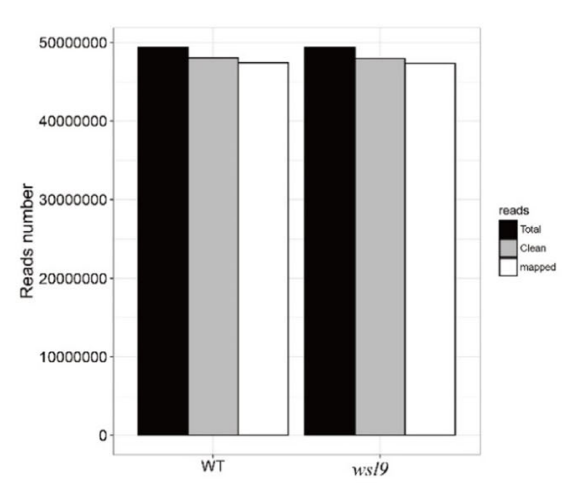

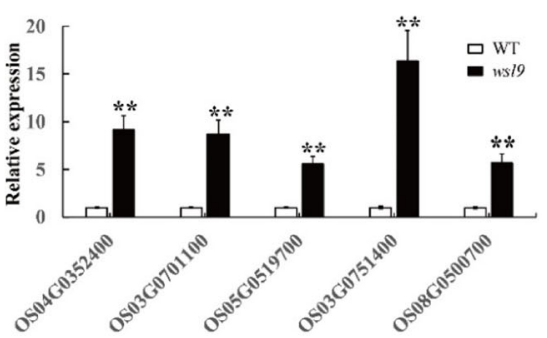

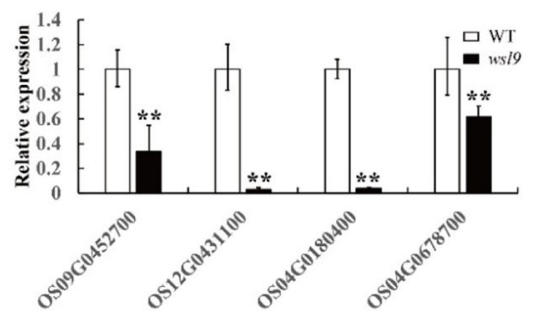

Fig. 9 RNA-seq analysis of wild-type and ws 19 seedlings under $20^{\circ} \mathrm{C}$ conditions. mRNA enriched from total RNA isolated from 10-d-old seedlings of WT and ws/9 mutant using oligo-(dT) was fragmented and reverse-transcribed using random hexamer primers. The library was then constructed and sequenced using an Illumina HiSEquation 2000. a Frequencies of detected genes sorted according to expression levels. $\mathbf{b}$ Read numbers of WT and ws 19 mutant sequences. c Volcano plot showing overall alterations in gene expression in WT and ws/9 mutant. $\mathbf{d}$ qRT-PCR of genes differentially expressed in RNA-seq. Five up-regulated and four down-regulated genes were assayed. Error bars represent SD from three independent experiments. (Student's $t$-test, ${ }^{* *}, P<0.01$ )

The editing efficiencies of rpoB at C467 and C560 were increased in wsl9 mutant compared with WT. This phenotypic defect is most reminiscent of the previously reported iojap mutant in maize and wsl4 mutant in rice in which the editing sites of $r p o B$ are both highly edited (Halter et al. 2004; Wang et al. 2017). According to the previous reports, codon $127-299$ and codon $779-802$ of $r p o B$ are located within Dispensable Region (Borukhov et al. 1991; Severinov et al. 1994), thus this Dispensable Region may be deleted without effect on the basic function of E.coli enzyme. It is possible that editing of the rpoB sites in Dispensable Region is non-essential (Corneille et al. 2000). C467 (codon 156) and C560 (codon 187) of $r p o B$ are located within Dispensable Region. Thus the abnormal editing site of $r p o B$ at Dispensable Region may not be responsible for the phenotype of $w s l 9$.

$r p l 2$ encodes $50 \mathrm{~S}$ ribosomal protein L2, and it is an crucial component of the translational apparatus in chloroplasts. Absence of this protein is a very sensitive marker for absence of ribosomal function, because it is involved in the peptidyl-transferase center (Nierhaus 1982). Therefore, low contents of L2 protein in ws 19 under low temperature (Fig.8c) indicated that the defective $r p l 2$ splicing possibly caused ribosome-deficient plastids. Impairment of the translational apparatus then resulted in defective chloroplast development. The phenomenon of "rpl2 not spliced" has also been found in the other white stripe mutants like wsl, wsl4 (Tan 
et al. 2014; Wang et al. 2017). Under low temperature, the rRNAs, including $23 \mathrm{~S}$ and $16 \mathrm{~S}$ rRNAs, were decreased in wsl9 (Fig. 6e, f). The absence of ribosomal protein RPL2 and rRNAs would obviously cause defects in ribosome biosynthesis, previous studies have shown that defects in the biogenesis of chloroplast ribosomes result in severe chlorotic phenotypes during early leaf development (Schmitz-Linneweber et al. 2006; Ostheimer et al. 2003; Song et al. 2014; Wang et al. 2016). We therefore propose that the mutation of WSL9 results in defective ribosome biogenesis under low temperature, which ultimately chloroplast development during early seedling growth. However, it is possible that there is a unknown mechanism that WSL9 regulates chloroplast development at low temperature, which will be our next research focus.

RNA-seq analysis was performed on wsl9 and wildtype plants grown at $20^{\circ} \mathrm{C}$ and $30^{\circ} \mathrm{C}$ to study the molecular mechanism of WSL9 in regulating chloroplast development under different temperature conditions. Our findings showed that under low temperature WSL9 regulates expression of genes, involved in carbohydrate metabolic processes, thylakoid membrane organization, ATP binding, oxidation-reduction process, chloroplast development (Additional file 9: Figure. S6). Many genes involved in regulating carbon dioxide process were dramatically changed in $w s l 9$ at low temperature such as OsLOX8, OsLOX9 indicating that mutation in wsl9 leads to defects in photosynthesis in young plants. RNA-seq data showed that the expression of WSL9 is decreased at $20{ }^{\circ} \mathrm{C}$ compared with $30^{\circ} \mathrm{C}$. Previous studies showed that not all Chl-deficient mutants are to be temperaturesensitive. TCD9 encodes a Cpn60 protein (tcd9) mutant, which exhibited the albino phenotype under low temperature whereas displayed normal green under high temperature; but the expression of TCD9 has no difference between $20^{\circ} \mathrm{C}$ and $30^{\circ} \mathrm{C}$ in wild type plants (Jiang et al. 2014). YSS1 encodes a chloroplast nucleoidassociated protein required for chloroplast development in rice seedlings, the phenotype of yss 1 mutant is severe at low temperature, but the expression of YSS1 is decreased at $20^{\circ} \mathrm{C}$ compared with $30^{\circ} \mathrm{C}$ (Zhou et al. 2016).

\section{Conclusions}

The WSL9 gene encodes a novel protein with an $\mathrm{HNH}$ motif. Disruption of WSL9 led to a white-striped seedling phenotype in the field, and temperature-sensitive phenotypes under controlled conditions. Further studies are required to uncover the role of WSL9 in chloroplast development.

\section{Methods \\ Plant Materials and Growing Conditions}

The wsl9 mutant was isolated from an ethylmethane sulfonate (EMS) mutagenesis mutant pool of japonica cultivar Ninggeng 3. Seedlings for studies on temperature effects were grown in a growth chamber with a $16 \mathrm{~h}$ light $/ 8 \mathrm{~h}$ photoperiod and constant temperatures of $20^{\circ} \mathrm{C}, 25^{\circ} \mathrm{C}$, and $30^{\circ} \mathrm{C}$. Nearly all analyses used third leaves at about 10 days post-germination.

\section{Measurement of Chlorophyll Contents}

Fresh leaves were collected and used to determine chlorophyll contents using a spectrophotometer and a previously described method (Arnon 1949). About $0.2 \mathrm{~g}$ of fresh leaves were collected in $10 \mathrm{ml}$ tubes, $5 \mathrm{ml}$ of $95 \%$ ethanol was added and tubes were held in darkness for $48 \mathrm{~h}$. Supernatants were then collected following centrifugation and analyzed with a DU 800 UV/Vis 102 Spectrophotometer (Beckman Coulter) at 665, 649 and 470 $\mathrm{nm}$, respectively.

\section{Transmission Electron Microscopy}

Leaves from WT and wsl9 seedlings for TEM analysis were cut into small pieces, fixed in $2.5 \%$ glutaraldehyde in phosphate buffer at $4{ }^{\circ} \mathrm{C}$ for $4 \mathrm{~h}$, rinsed, and incubated overnight in $1 \% \mathrm{w} / \mathrm{v} \mathrm{OsO}_{4}$ at $4{ }^{\circ} \mathrm{C}$. The tissues were then dehydrated in an ethanol series and embedded in Spurr's medium prior to thin sectioning. The samples were examined with a Hitachi H-7650 transmission electron microscope.

\section{Map-Based Cloning of the WSL9 Allele and Complementation of ws 19}

Genetic analysis was performed on $F_{2}$ populations from reciprocal crosses Ninggeng $3 \times$ ws $l 9$ and $w s l 9 \times$ Ninggeng 3 . An $\mathrm{F}_{2}$ mapping population was constructed from the cross wsl9 mutant $\times 93-11 ; 768$ plants with the wsl9 phenotype were used for fine mapping. New SSR/InDel markers were developed based on the Nipponbare and 93-11 (indica) genome sequences (http://www.gramene. org/). Primers were designed with Primer Premier 5.0. The PCR-based molecular markers used in the study are listed in Additional file 1: Table S1. The PCR cycling protocol comprised an initial denaturation step $\left(95^{\circ} \mathrm{C} / 5\right.$ min), followed by 35 cycles of $94^{\circ} \mathrm{C} / 30 \mathrm{~s}, 55^{\circ} \mathrm{C} / 30 \mathrm{~s}$, and $72{ }^{\circ} \mathrm{C} / 34 \mathrm{~s}$, with a final extension step of $72^{\circ} \mathrm{C} / 5 \mathrm{~min}$.

\section{Complementation Tests}

The WSL9 locus was narrowed to a $89 \mathrm{~kb}$ genomic region flanked by InDel markers N12 and N3-11 on the long arm of chromosome 3 (Additional file 1: Table. S1). For complementation of the wsl9 mutation, $\mathrm{a} \sim 2.1 \mathrm{~kb}$ upstream sequence and a 564 bp WT CDS fragment were amplified from the WT (primer CWSL9 pairs and 
PWSL9 (Additional file 3: Table S3)), and cloned into binary vector pCAMBIA1390 to generate a pCAMBIA1390-WSL9 vector. This plasmid was introduced into wsl9 mutants by agroinfection (Hiei et al. 1994).

\section{Sequence and Phylogenetic Analyses}

Gene prediction and structure analysis were performed using the GRAMENE database (www.gramene.org/). Homologous sequences of WSL9 were identified using the Blastp search program of the National Center for Biotechnology Information (NCBI, www.ncbi.nlm.nih. gov/). Multiple sequence alignments were conducted with DNAMAN. A phylogenetic tree was constructed using MEGA7 software.

\section{RT-PCR and Quantitative Real-Time PCR (qRT-PCR)}

Total rice RNA was extracted with an RNA prep pure plant kit (TIANGEN, Beijing). The cDNA first strand was reverse-transcribed using oligo $(\mathrm{dT})$ as primer. $\mathrm{qRT}-$ PCR was conducted using an ABI7500 real-time PCR system with the SYBR Green MIX in three biological repeats. Gene-specific primers used in real-time PCR are listed in Additional file 2: Table S2. The rice Ubiquitin gene was used as an internal control.

\section{RNA Analysis}

Total RNA was isolated from third leaves of WT and wsl9 seedlings. RNA samples were diluted to $10 \mathrm{ng} / \mathrm{mL}$ and analyzed using an Agilent 2100 analyzer. An RNA 6000 Nano Total RNA Analysis kit (Agilent) was used to measure concentrations.

\section{RNA Editing Sites}

Specific cDNA fragments were generated by PCR amplification following established protocols with the respective primers (Takenaka and Brennicke 2007). The cDNA sequences were compared. The primers used for RNA editing analysis were obtained as reported previously (Tan et al. 2014).

\section{RNA Splicing Analysis}

The chloroplast gene with at least one intron was selected and amplified using RT-PCR with primers flanking the introns. The primers used for RNA splicing analysis are listed in Table S2.

\section{RNA-Seq Analysis}

RNA-sequencing (RNA-seq) analyses were performed on an Illumina Hiseq2000/2500 (LC Sciences) following the vendor's recommended protocol and single end sequencing was performed on an Illumina Hiseq2500 instrument (OE Biotech, Shanghai). Significantly differentially expressed genes were identified based on a $P$-value of $\leq 0.05$ and a $\log 2$ fold-change of $(\log 2$ FC $) \geq 2$. Ontology analyses of these genes were carried out by referring to GOseq (Young et al. 2010). Pathway enrichment analyses were conducted using the Kyoto Encyclopedia of Genes and Genomes (KEGG) database (Kanehisa et al. 2008).

\section{Supplementary information}

Supplementary information accompanies this paper at https://doi.org/10. 1186/s12284-020-00407-2.

Additional file 1: Table S1. Newly designed PCR primers used for gene mapping.

Additional file 2: Table S2. Primers for quantitative real-time PCR, RNA splicing.

Additional file 3: Table S3. Primers used for vector construction.

Additional file 4: Figure S1. Phylogenic analysis of WSL9. a Structure of WSL9. b Evolutionary analysis of WSL9 and its homologs. c Alignment of amino acid sequences with highest identity to WSL9. Red arrow indicates the position of amino acid change in the wsl9 mutant.

Additional file 5: Figure S2. Expression profiles of the WSL9 gene from http://ricexpro.dna.affrc.go.jp/.

Additional file 6: Figure S3. Editing efficiencies of $r p o B$ genes in WT, ws 19 mutant and complemented plants at different temperature. RT-PCR products of rpoB transcripts of WT, ws $/ 9$ mutant, and complemented plants (WSL-COm) grown in a growth chamber were sequenced. Editing efficiencies of rpoB at C467 and C560 in ws/9 mutant were significantly in creased compared to $\mathrm{WT}$ and complementation plants (Com) at $20^{\circ} \mathrm{C}$. Green, black, red, and blue peaks represent $A, G, T$, and $C$, respectively. Red boxes indicate editing sites.

Additional file 7: Figure S4. Expression levels of chlorophyll synthesis genes in wild type and ws/9 mutant. (Student's $t$-test, $* *, P<0.01$ ).

Additional file 8: Figure S5. RNA-seq analysis of WT and ws 19 seedlings at $30^{\circ} \mathrm{C}$. mRNA was enriched from total RNA isolated from 10-d-old WT and ws/9 mutant seedlings using oligo-(dT) fragmented and reversetranscribed using random hexamer primers. The library was then constructed and sequenced using an Illumina HiSEquation 2000. a Frequencies of detected genes sorted according to expression level. b Read numbers of WT and ws $/ 9$ mutant sequences. c Volcano plot showing overall alterations in gene expression in WT and ws/9 mutant.

Additional file 9: Figure S6. RNA-seq analysis of WT and ws/9 mutant grown at $20^{\circ} \mathrm{C}$ and $30^{\circ} \mathrm{C}$. a Up-regulated differentially expressed genes comparing $\mathrm{M} 2$ and $\mathrm{W} 2$ and $\mathrm{M} 3$ and $\mathrm{W} 3$. b Down-regulated differentially expressed genes for M2-vs-W2 and M3-vs-W3. c Go analysis of genes differentially expressed between $M 2$ and W2. d Go analysis of genes differentially expressed for M3-vs-W3. W3 and W2 represent WT plants grown at $30^{\circ} \mathrm{C}$ and $20^{\circ} \mathrm{C}$, respectively. $\mathrm{M} 3$ and $\mathrm{M} 2$ represent ws $/ 9$ mutant plants grown at $30^{\circ} \mathrm{C}$ and $20^{\circ} \mathrm{C}$, respectively.

\section{Abbreviations}

WT: Wild type; GO: Gene ontology; qRT-PCR: Quantitative real-time polymerase chain reaction; RNA-seq: RNA sequencing; TEM: Transmission electron microscopy

\section{Authors' Contributions}

ZXJ, JL and WJM conceived and designed the experiments. ZXJ, MCL, ZFL, HYS, YCY, JJL, LX, CPH, NTL, $\sqcup$ and ZCL performed the experiments and analyzed the data. LSJ was responsible for material plant and field management. ZXJ wrote the manuscript. JL and WJM revised the manuscript. All authors read and approved the manuscript.

\section{Author Information}

Correspondence and requests for materials should be addressed to Ling Jiang (jiangling@njau.edu.cn) and Jianmin Wan (wanjm@njau.edu.cn).

\section{Funding}

This research was supported by the grants from National Transformation Science and Technology Program (2016ZX08001006), the National Key 
Research and Development Program of China (2016YFD0100101-08), National Natural Science Foundation of China (31871712), Jiangsu Science and Technology Development Program (BE2018388), and the Project for Major New Varieties of Agriculture in Jiangsu province (PZCZ201701).

\section{Availability of Data and Materials}

All data supporting the conclusions of this article are provided within the article (and its additional files).

\section{Ethics Approval and Consent to Participate}

There are no ethics issues associated with this article.

\section{Consent for Publication}

These co-authors involved in the paper all consent to publish this article in Rice.

\section{Competing Interests}

The authors declare that they have no competing interests.

\begin{abstract}
Author details
'State Key Laboratory for Crop Genetics and Germplasm Enhancement, Jiangsu Plant Gene Engineering Research Center, Nanjing Agricultural University, Nanjing 210095, China. ${ }^{2}$ Department of Biology and Agricultural Engineering, Quynhon University, Quynhon, Binhdinh 590000, Vietnam. ${ }^{3}$ National Key Facility for Crop Gene Resources and Genetic Improvement, Institute of Crop Science, Chinese Academy of Agricultural Sciences, Beijing 100081, China
\end{abstract}

\section{Received: 2 September 2019 Accepted: 6 July 2020}

Published online: 11 July 2020

\section{References}

Andrews TJ (1996) The bait in the Rubisco mousetrap. Nat Struct Biol 3:3-7

Arnon DI (1949) Copper enzymes in isolated chloroplasts. Polyphenoloxidase in Beta vulgaris. Plant Physiol 24:1-15

Borukhov S, Severinov K, Kashlev M (1991) Mapping of trypsin cleavage and antibody-binding sites and delineation of a dispensable domain in the beta subunit of Escherichia coli RNA polymerase. J Biol Chem 266:23921-23926

Cao P, Ren Y, Liu X, Zhang T, Zhang P, Xiao L, Zhang F, Liu S, Jiang L, Wan J (2019) Purine nucleotide biosynthetic gene GARS controls early chloroplast development in rice (Oryza sativa L.). Plant Cell Rep 38:183-194

Castandet B, Choury D, Begu D, Jordana X, Araya A (2010) Intron RNA editing is essential for splicing in plant mitochondria. Nucleic Acids Res 38:7112-7121

Corneille S, Lutz K, Maliga P (2000) Conservation of RNA editing between rice and maize plastids: are most editing events dispensable? Mol Gen Genet 264:419-424

Covello PS, Gray MW (1989) RNA editing in plant mitochondria. Nature 341:662666

Cymerman IA, Obarska A, Skowronek K, Lubys A, Bujnicki JM (2006) Identification of a new subfamily of $\mathrm{HNH}$ nucleases and experimental characterization of a representative member, Hphl restriction endonuclease. Proteins 65:867-876

de Longevialle AF, Small ID, Lurin C (2010) Nuclearly encoded splicing factors implicated in RNA splicing in higher plant organelles. Mol Plant 3:691-705

Erickson JM, Rahire M, Rochaix JD (1984) Chlamydomonas reinhardtii gene for the 32000 Mol.Wt. protein of photosystem II contains four large introns and is located entirely within the chloroplast inverted repeat. EMBO J 3:2753-2762

Farre JC, Aknin C, Araya A, Castandet B (2012) RNA editing in mitochondrial trans-introns is required for splicing. PLoS One 7:e52644

Galburt EA, Stoddard BL (2002) Catalytic mechanisms of restriction and homing endonucleases. Biochemistry 41:13851-13860

Gong X, Su Q, Lin D, Jiang Q, Xu J, Zhang J, Teng S, Dong Y (2014) The rice OsV4 encoding a novel pentatricopeptide repeat protein is required for chloroplast development during the early leaf stage under cold stress. J Integr Plant Biol $56: 400-410$

Hajdukiewicz PTJ, Allison LA, Maliga P (1997) The two RNA polymerases encoded by the nuclear and the plastid compartments transcribe distinct groups of genes in tobacco plastids. EMBO J 16:4041-4048

Halter CP, Peeters NM, Hanson MR (2004) RNA editing in ribosome-less plastids of iojap maize. Curr Genet 45:331-337

Hedtke, Börner, Weihe (1997) Mitochondrial and chloroplast phage-type RNA polymerases in Arabidopsis. Science 277:809-811
Hiei Y, Ohta S, Komari T, Kumashiro T (1994) Efficient transformation of rice (Oryza sativa $\mathrm{L}$.) mediated by agrobacterium and sequence analysis of the boundaries of the T-DNA. Plant J 6:271-282

Hiratsuka J, Shimada H, Whittier R, Ishibashi T, Sakamoto M, Mori M, Kondo C, HonjiY SC, Meng B, Li Y, Kanno A, Nishizawa Y, Hirai A, Shinozaki K, Sugiura M (1989) The complete sequence of the rice (Oryza sativa) chloroplast genome: intermolecular recombination between distinct tRNA genes accounts for a major plastid DNA inversion during the evolution of the cereals. Mol Gen Genet 217:185-194

Hoch B (1991) Editing to a chloroplast mRNA by creation of an initiation codon. Nature 353:178-180

Holloway SP, Deshpande NN, Herrin DL (1999) The catalytic group-l introns of the psbA gene of Chlamydomonas reinhardtii: core structures, ORFs and evolutionary implications. Curr Genet 36:69-78

Hsia KC, Chak KF, Liang PH, Cheng YS, Ku WY, Yuan HS (2004) DNA binding and degradation by the HNH protein ColE7. Structure 12:205-214

Hubschmann T, Hess WR, Börner T (1996) Impaired splicing of the rps 12 transcript in ribosome-deficient plastids. Plant Mol Biol 30:109-123

Ichinose M, Sugita M (2016) RNA editing and its molecular mechanism in plant organelles. Genes 8:5

Jarvis P, López-Juez E (2013) Biogenesis and homeostasis of chloroplasts and other plastids. Nat Rev Mol Cell Biol 14:787-802

Jiang Q, Mei J, Gong XD, Xu JL, Zhang JH, Teng S, Lin DZ, Dong YJ (2014) Importance of the rice TCD9 encoding a subunit of chaperonin protein 60 (Cpn60a) for the chloroplast development during the early leaf stage. Plant Sci 215-216:172-179

Kanehisa M, Araki M, Goto S, Hattori M, Hirakawa M, Itoh M, Katayama T, KawashimaS OS, Tokimatsu T, Yamanishi Y (2008) KEGG for linking genomes to life and the environment. Nucleic Acids Res 36:480-484

Ku WY, Liu YW, Hsu YC, Liao CC, Liang PH, Yuan HS, Chak KF (2002) The zinc ion in the $\mathrm{HNH}$ motif of the endonuclease domain of colicin E7 is not required for DNA binding but is essential for DNA hydrolysis. Nucleic Acids Res 30: 1670-1678

Kusumi K, Sakata C, Nakamura T, Kawasaki S, Yoshimura A, lba K (2011) A plastid protein NUS1 is essential for build-up of the genetic system for early chloroplast development under cold stress conditions. Plant J 68:1039-1050

Liere K, Weihe A, Börner T (2011) The transcription machineries of plant mitochondria and chloroplasts: composition, function, and regulation. J Plant Physiol 18:1345-1360

Liu X, Lan J, Huang Y, Cao P, Zhou C, Ren Y, He N, Liu S, Tian Y, Nguyen T, Jiang L, Wan J (2018) WSL5, a pentatricopeptide repeat protein, is essential for chloroplast biogenesis in rice under cold stress. J Exp Bot 69:3949-3961

Mandel MA, Feldmann KA, Herrera-Estrella L, Rocha-Sosa M, Leon P (1996) CLA1, a novel gene required for chloroplast development, is highly conserved in evolution. Plant J 9:649-658

Mehta P, Katta K, Krishnaswamy S (2004) HNH family subclassification leads to commonality in the his-me endonuclease superfamily. Protein Sci 13:295-300

Nierhaus KH (1982) Structure, assembly, and function of ribosomes. Curr Top Microbiol Immunol 97:81-155

Ostheimer GJ, Williams-Carrier R, Belcher S, Osborne E, Gierke J, Barkan A (2003) Group II intron splicing factors derived by diversification of an ancient RNAbinding domain. EMBO J 22:3919-3929

Pommer AJ, Kühlmann UC, Cooper A, Hemmings AM, Moore GR, James R, Kleanthous C (1999) Homing in on the role of transition metals in the $\mathrm{HNH}$ motif of colicin endonucleases. J Biol Chem 274:27153-27160

Ramirez-Garcés D, Camborde L, Pel MJ, Jauneau A, Martinez Y, Néant I, Leclerc C, Moeau M, Dumas B, Gaulin E (2015) CRN13 candidate effectors from plant and animal eukaryotic pathogens are DNA-binding proteins which trigger host DNA damage response. New Phytol 210:602-617

Sakamoto W, Miyagishima SY, Jarvis P (2008) Chloroplast biogenesis: control of plastid development, protein import, division and inheritance. Arabidopsis Book 6:e0110

Saravanan M, Bujnicki JM, Cymerman IA, Rao DN, Nagaraja V (2004) Type ॥ restriction endonuclease $\mathrm{R}$. Kpnl is a member of the $\mathrm{HNH}$ nuclease superfamily. Nucleic Acids Res 32:6129-6135

Schmitz-Linneweber C, Williams-Carrier RE, Williams-Voelker PM, Kroeger TS, Vichas A, Barkan A (2006) A pentatricopeptide repeat protein facilitates the trans-splicing of the maize chloroplast rps12 pre-mRNA. Plant Cell 18:26502663 
Severinov K, Kashlev M, Severinova E (1994) A non-essential domain of Escherichia coli RNA polymerase required for the action of the termination factor Alc. J Biol Chem 269:14254-14259

Shen BW, Landthaler M, Shub DA, Stoddard BL (2004) DNA binding and cleavage by the HNH homing endonuclease I-Hmul. J Mol Biol 342:43-56

Song J, Wei X, Shao G, Sheng Z, Chen D, Liu C, Jiao G, Xie L, Tang S, Hu P (2014) The rice nuclear gene WLP1 encoding a chloroplast ribosome L13 protein is needed for chloroplast development in rice grown under low temperature conditions. Plant Mol Biol 84:301-314

Spreitzer RJ, Salvucci ME (2002) RUBISCO: structure, regulatory interactions, and possibilities for a better enzyme. Annu Rev Plant Biol 53:449-475

Stoddard BL (2006) Homing endonuclease structure and function. Q Rev Biophys 38:49-95

Su N, Hu M, Wu D, Wu F, Fei G, Lan Y, Chen X, Shu X, Zhang X, Guo X, Cheng Z, Lei C, Qi C, Jiang L, Wang H, Wan J (2012) Disruption of a rice pentatricopeptide repeat protein causes a seedling-specific albino phenotype and its utilization to enhance seed purity in hybrid rice production. Plant Physiol 159:227-238

Sugimoto H, Kusumi K, Noguchi K, Yano M, Yoshimura A, Iba K (2007) The rice nuclear gene, VIRESCENT 2, is essential for chloroplast development and encodes a novel type of guanylate kinase targeted to plastids and mitochondria. Plant J 52:512-527

Swiatecka-Hagenbruch M, Liere K, Börner T (2007) High diversity of plastidial promoters in Arabidopsis thaliana. Mol Gen Genomics 277:725-734

Takenaka M, Brennicke A (2007) RNA editing in plant mitochondria: assays and biochemical approaches. Methods Enzymol 424:439-458

Tan J, Tan Z, Wu F, Sheng P, Heng Y, Wang X, Ren Y, Wang J, Guo X, Zhang X, Cheng Z, Jiang L, Liu X, Wang H, Wan J (2014) A novel chloroplast-localized pentatricopeptide repeat protein involved in splicing affects chloroplast development and abiotic stress response in rice. Mol Plant 7:1329-1349

Tang J, Zhang W, Wen K, Chen G, Sun J, Tian Y, Tang W, Yu J, An H, Wu T, Kong Terzaghi W, Wang C, Wan J (2017) OsPPR6, a pentatricopeptide repeat protein involved in editing and splicing chloroplast RNA, is required for chloroplast biogenesis in rice. Plant Mol Biol 95:345-357

Tiller N, Bock R (2014) The translational apparatus of plastids and its role in plant development. Mol Plant 7:1105-1120

Tillich M, Krause K (2010) The ins and outs of editing and splicing of plastid RNAs: lessons from parasitic plants. New Biotechnol 27:256-266

Wang Y, Ren Y, Zhou K, Liu L, Wang J, Xu Y, Zhang H, Zhang L, Feng Z, Wang L, Ma W, Wang Y, Guo X, Zhang X, Lei C, Cheng Z, Wan J (2017) WHITE STRIPE LEAF4 encodes a novel p-type PPR protein required for chloroplast biogenesis during early LEAF development. Front Plant Sci 8:1116

Wang Y, Wang C, Zheng M, Lyu J, Xu Y, Li X, Niu M, Long W, Wang D, Wang $H$, Terzaghi W, Wang Y, Wan J (2016) WHITE PANICLE1, a Val-tRNA synthetase regulating chloroplast ribosome biogenesis in rice, is essential for early chloroplast development. Plant Physiol 170:2110-2123

Xiao H, Xu Y, Ni C, Zhang Q, Zhong F, Huang J, Liu W, Peng Y, Zhu Y, Hu J (2018) A rice dual-localized pentatricopeptide repeat protein is involved in organellar RNA editing together with OsMORFs. J Exp Bot 69:2923-2936

Yoo SC, Cho SH, Sugimoto H, Li J, Kusumi K, Koh HJ, Iba K, Paek NC (2009) Rice virescent 3 and stripe 1 encoding the large and small subunits of ribonucleotide reductasearerequired for chloroplast biogenesis during early leaf development. Plant Physiol 150:388-401

Young MD, Wakefield MJ, Smyth GK, Oshlack A (2010) Gene ontology analysis for RNA-seq: accounting for selection bias. Genome Biol 11:1-12

Zhang T, Feng P, Yu P, Yu G, Sang X, Ling Y, Zeng X, Li Y, Huang J, Zhang T, Zhao F, Wang N, Zhang C, Yang Z, Wu R, He G (2018) VIRESCENT-ALBINO LEAF1 regulates LEAF colour development and cell division in rice. J Exp Bot 69:4791-4804

Zhang Z, Cui X, Wang Y, Wu J, Gu X, Lu T (2017) The RNA editing factor WSP1 is essential for chloroplast development in rice. Mol Plant 10:86-89

Zhou K, Ren Y, Zhou F, Wang Y, Zhang L, Lyu J, Wang Y, Zhao S, Ma W, Zhang H, Wang L, Wang C, Wu F, Zhang X, Guo X, Cheng Z, Wang J, Lei C, Jiang L, Li Z, Wan J (2016) Young Seedling Stripel encodes a chloroplast nucleoidassociated protein required for chloroplast development in rice seedlings. Planta 245:1-16

\section{Publisher's Note}

Springer Nature remains neutral with regard to jurisdictional claims in published maps and institutional affiliations.

\section{Submit your manuscript to a SpringerOpen ${ }^{\circ}$ journal and benefit from:}

- Convenient online submission

- Rigorous peer review

- Open access: articles freely available online

- High visibility within the field

- Retaining the copyright to your article

Submit your next manuscript at $\boldsymbol{\nabla}$ springeropen.com 